\title{
Experimental hypercalcaemia and whole blood clotting
}

\author{
P. HILGARD ${ }^{1}$
}

From the Section of Coagulation Research, Centre of Internal Medicine and Paediatrics, University of Ulm, $79 \mathrm{Ulm} /$ Donau, Germany

SYNOPSIS Experimental hypercalcaemia was induced in rats by (1) transplantation of the solid Walker 256 tumour, and (2) intraperitoneal injections of calcium gluconate. Whole blood clotting was studied by means of thromboelastography and whole blood clotting times in polystyrene and glass test tubes. At serum calcium levels between 10.3 and $11.5 \mathrm{~m}$-equiv/l a slight delay in clot formation was found which was reversible by the addition of EDTA to whole blood. Acute, calciumgluconate-induced hypercalcaemia, however, leads to a significant shortening of the clotting time in the polystyrene tube and to a lesser degree in the glass tube. Maximal factor XII activation in vitro with ellagic acid levels the difference of clotting times again. From these experiments it is concluded that acute hypercalcaemia induces a hypercoagulable state, possibly by partial contact activation, and thus may favour thrombus formation in vivo.

It is well established that the presence of calcium ions is essential during the course of the enzymatic cascade of blood coagulation. In vitro the calcium concentration may be reduced by at least one half before any defect in blood clotting is observed (Stefanini and Dameshek, 1962), and in clinical conditions obviously hypocalcaemia causes severe systemic disturbances before blood clotting is affected. On the other hand hypercalcaemia due to various pathological conditions is a frequent clinical observation. Since thrombotic disorders in association with acute hyperparathyroidism have been reported (Mellgren, 1943; Pringle and Smith, 1964; Baer and Neu, 1966), hypercalcaemia has been considered to be one of the trigger mechanisms for thrombus formation in vivo (McKay, 1965). There is no clear conception as to how calcium is involved in the initiation of clotting.

Recently the coincidence of a coagulation disturbance and excessive hypercalcaemia has been described in an experimental rat tumour (Hilgard, Schmitt, Minne, and Ziegler, 1970). Concomitantly with the hypercalcaemia syndrome these tumourbearing animals developed a coagulopathy related to intravascular coagulation (Hilgard, Ziegler, Minne, and Schmitt, 1971) and in addition there was evidence that the raised blood calcium level was involved in

'Present address: Department of Haematology, Royal Postgraduate Medical School, London W12 0HS

Received for publication 1 June 1973. the clotting defect. The present investigations were designed to elucidate the interrelation between hypercalcaemia and whole blood clotting and to make a contribution to the understanding of a possible pathogenetic role of a raised calcium level in thrombosis.

\section{Material and Methods}

Female Sprague-Dawley derived SIV-50 rats, weighing 100 to $180 \mathrm{~g}$, were used throughout the experiments. Blood samples were obtained under ether anaesthesia by cannulation of the abdominal aorta with a polyethylene catheter. The initial 0.5 to $1.0 \mathrm{ml}$ of blood was rejected.

Half a millilitre of freshly harvested ascitic Walker 256 tumour was injected intramuscularly into the right upper thigh of the animals. Six days after the tumour transplantation the serum calcium level had increased from $4.5( \pm 0.1)$ m-equiv/l to $10.3( \pm 0.2)$ m-equiv/l (Minne, Ziegler, Schmitt, and Hilgard, 1971) and the animals were bled at that time.

Acute hypercalcaemia was induced in the animals according to Duffy, Suzuki, and Churg (1971) by injecting $0.016 \mathrm{ml}$ per gram body weight of a $10 \%$ calcium gluconate solution intraperitoneally. Control animals received the same amount of a $10 \%$ sodium gluconate solution intraperitoneally. Blood samples were taken 90 minutes after the injection by which 
time the serum calcium level had increased from 4.5 $( \pm 0 \cdot 1) \mathrm{m}$-equiv/l to $11.5( \pm 1 \cdot 3) \mathrm{m}$-equiv/l.

Whole blood thromboelastography was performed in untreated control $(n=30)$, hypercalcaemic tumour animals $(n=10)$ calcium-gluconate $(\mathrm{n}=12)$ and sodium-gluconate $(\mathrm{n}=12)$-treated animals, by allowing the blood to drop directly into the cuvette. In some additional cases $0.05 \mathrm{ml}$ of a $0.1 \%$ EDTA-saline solution or $0.05 \mathrm{ml}$ saline was added to the cuvette. The thrombelastogram was evaluated by measuring the clotting time (r), the clot-forming time (k), and the maximal width $\left(\mathrm{a}_{\max }\right)$ in $\mathrm{mm}$.

Whole blood clotting times were performed by collecting $0.5 \mathrm{ml}$ of blood into three prewarmed polystyrene and three prewarmed glass tubes which were incubated in a $37^{\circ} \mathrm{C}$ water bath. At 30 -second intervals the first tubes were tilted until clotting occurred and this was repeated with the subsequent tubes. The clotting times of the third polystyrene and glass tubes were recorded.

Whole blood clotting times with maximal factor XII activation were done in glass tubes containing $0.1 \mathrm{ml} 10^{-4} \mathrm{~m}$ ellagic acid, which was prepared according to Ratnoff and Crum (1964). One ml of whole blood was added, the tubes were continuously tilted in a $37^{\circ}$ water bath, and the clotting time was recorded.

\section{Statistical Evaluation}

The mean values and the standard deviations were calculated. The significance of the results was determined by the Student's $t$ test and the probability (P) was evaluated.

\section{Results}

Table I demonstrates the mean thromboelastogram values in untreated control animals, tumourbearing animals, and in sodium-gluconate and calcium-gluconate-treated animals. The tumour animals show a distinct coagulopathy with prolongation of the clotting time ( $r$ ) and prolongation of the clot-forming time $(k)$; both are significant at $1 \%$ levels $(P=0.01)$ if compared with the untreated and sodium-gluconate-treated control groups. The maximal width is slightly decreased, although this is not significant at this stage of tumour growth. By contrast, in the calcium-gluconate-treated animals the clotting time ( $r)$ is significantly shortened $(P<$ 0.02 ) but nevertheless there is a prolongation of the clot-forming time $(P=0.01)$ in these animals. The common feature in the shape of the thromboelastogram in both hypercalcaemic groups is the delay in clot formation.

The addition of EDTA to the cuvette resulted in a decrease in the clot-forming time (k) in calciumgluconate-treated animals $(n=5)$ compared with the thromboelastogram where only saline was added ( $\mathrm{n}=5$, table II). The EDTA also induced a slight reduction in the clotting time (r) and the clot-forming time $(k)$ in the hypercalcaemic tumour animals $(n=6)$. The addition of the same amount of

\begin{tabular}{|c|c|c|c|c|c|c|c|c|}
\hline & \multicolumn{2}{|l|}{ Mean Serum } & \multicolumn{2}{|c|}{ r-Time (min) } & \multicolumn{2}{|c|}{$k$-Time (min) } & \multicolumn{2}{|c|}{$a_{\max }(\mathrm{mm})$} \\
\hline & $C a(m E q \mid l)$ & No. & Mean & $S D$ & Mean & $S D$ & Mean & $S D$ \\
\hline $\begin{array}{l}\text { Untreated } \\
\text { Tumour day } 6 \\
\text { Sodium gluconate } \\
\text { Calcium gluconate }\end{array}$ & $\begin{array}{r}4 \cdot 5 \\
10 \cdot 3 \\
4 \cdot 4 \\
11 \cdot 5\end{array}$ & $\begin{array}{l}30 \\
10 \\
12 \\
12\end{array}$ & $\begin{array}{l}4 \cdot 5 \\
9 \cdot 4 \\
4 \cdot 2 \\
2 \cdot 2\end{array}$ & $\begin{array}{l}1 \cdot 75 \\
2 \cdot 4 \\
1 \cdot 5 \\
0 \cdot 8\end{array}$ & $\begin{array}{l}1 \cdot 75 \\
5 \cdot 1 \\
1 \cdot 75 \\
3 \cdot 2\end{array}$ & $\begin{array}{l}0.25 \\
1.2 \\
0.25 \\
0.4\end{array}$ & $\begin{array}{l}71 \\
59 \\
73 \\
69\end{array}$ & $\begin{array}{l}3 \cdot 5 \\
4 \cdot 2 \\
3 \cdot 1 \\
4 \cdot 0\end{array}$ \\
\hline
\end{tabular}

Table I Whole blood thrombelastography in untreated, sodium and calcium gluconate treated and hypercalcaemic tumour rats

\begin{tabular}{|c|c|c|c|c|c|c|c|}
\hline & \multirow[t]{2}{*}{ No. } & \multicolumn{2}{|c|}{ r-Time (min) } & \multicolumn{2}{|c|}{$k$-Time (min) } & \multicolumn{2}{|c|}{$a_{\max }(m m)$} \\
\hline & & Mean & $S D$ & Mean & $S D$ & Mean & $S D$ \\
\hline $\begin{array}{l}\text { Untreated + saline } \\
\text { Untreated + EDTA } \\
\text { Tumour day } 6+\text { saline } \\
\text { Tumour day } 6+\text { EDTA } \\
\text { Calcium gluconate + saline } \\
\text { Calcium gluconate + EDTA }\end{array}$ & $\begin{array}{l}6 \\
6 \\
6 \\
6 \\
5 \\
5\end{array}$ & $\begin{array}{l}4 \cdot 7 \\
6 \cdot 5 \\
8 \cdot 8 \\
6 \cdot 7 \\
3 \cdot 0 \\
3 \cdot 5\end{array}$ & $\begin{array}{l}1.9 \\
2.0 \\
2.5 \\
2 \cdot 2 \\
1.7 \\
1.5\end{array}$ & $\begin{array}{l}1 \cdot 75 \\
3 \cdot 4 \\
4 \cdot 75 \\
3 \cdot 5 \\
3 \cdot 0 \\
1 \cdot 75\end{array}$ & $\begin{array}{l}0.25 \\
0.75 \\
0.5 \\
0.5 \\
0.5 \\
0.25\end{array}$ & $\begin{array}{l}70 \\
71 \\
61 \\
67 \\
68 \\
69\end{array}$ & $\begin{array}{l}4 \cdot 5 \\
6 \cdot 3 \\
4 \cdot 9 \\
3 \cdot 8 \\
5 \cdot 1 \\
6 \cdot 4\end{array}$ \\
\hline
\end{tabular}

Table II Whole blood thromboelastography in untreated, calcium-gluconate-treated, and hypercalcaemic tumour rats after addition of $0.05 \mathrm{ml}$ saline or $1 \%$ EDTA solution to the cuvette 
EDTA to whole blood from untreated rats $(n=5)$ resulted in a slight prolongation of the clotting time (r) and clot-forming time (k).

The fig shows the whole blood clotting times of sodium- and calcium-gluconate-treated animals in polystyrene and glass tubes. The mean clotting time in polystyrene tubes was $11.7( \pm 2.5)$ minutes in the control group $(n=14)$ and $6.6( \pm 1.25)$ minutes in the calcium-treated group $(n=14)$. The difference is highly significant $(P<0.01)$. In glass tubes there is still a difference $(P=0.02)$ between the two groups, the mean value being $2.4( \pm 0.2)$ minutes for the control $(n=12)$ and $1.8( \pm 0.3)$ minutes for the calcium-treated group $(n=12)$. The addition of ellagic acid resulted in a complete equalization of the differences of the clotting times between control and calcium-treated animals; $53.6( \pm 5.3)$ seconds was the mean value for the calcium-treated rats $(n=12)$ and $50 \cdot 0( \pm 5 \cdot 2)$ seconds for the control rats $(n=12)$.

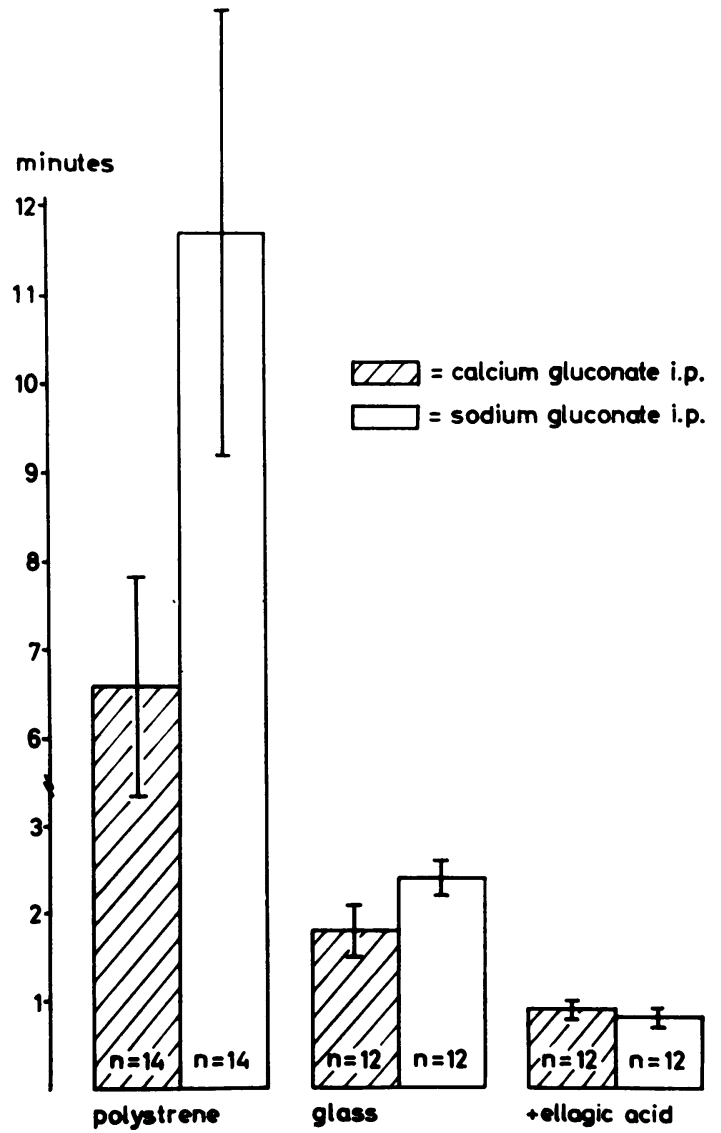

Fig Whole blood clotting times in polystyrene and glass test tubes and after addition of ellagic acid in sodium-and calcium-gluconate-treated rats.

\section{Discussion}

The thromboelastograms of hypercalcaemic tumour animals show a clotting defect with prolongation of the clotting and clot-forming times. Previous studies of the coagulation system during the growth of the solid Walker 256 tumour revealed the development of intravascular coagulation in the course of tumour growth and the coagulopathy was interpreted as being due to consumption of various clotting factors (Hilgard, Hohage, Schmitt, and Köhle, 1973). However, the present study showed that the addition of EDTA to whole blood of hypercalcaemic tumour animals results in a slight improvement in the clotting defect, suggesting that the elevated serum calcium level might be additionally involved in this condition. To study the effect of acute hypercalcaemia on blood coagulation, hypercalcaemia was induced by intraperitoneal calcium gluconate injections. At the time of bleeding the animals the serum calcium level had increased to values comparable to those found in the tumour animals. At that time the whole blood thrombelastogram showed a decreased clotting time but nevertheless there was a slight prolongation of the clotforming time. Both changes were reversible by the addition of EDTA. Since EDTA in the same concentration prolonged the clotting and clot-forming time of normocalaemic control animals, it became evident that the changes in whole blood thromboelastography in acute experimental hypercalcaemia were related to the high serum calcium levels.

The clot-forming time is closely related to the polymerization of fibrin. In vitro calcium ions are not essential for the conversion of fibrinogen to fibrin; however, their presence has an accelerating effect upon this reaction (Rosenfeld and Jánszky, 1952; Boyer, Shainoff, and Ratnoff, 1972). It was suggested that divalent cations favour fibrin polymerization by an 'attractive' interaction with certain carboxyl sites of fibrin monomers (Marguerie, Hudry, and Hollard, 1970). Increasing calcium levels prolong the plasma clotting time in various assay systems (Tocantins and Kazal, 1964) and a delay in fibrin formation in a purified system in the presence of an excess of calcium ions has been reported. This excess of calcium ions is considered to lead to an overloading of the monomer molecule with positively charged ions resulting in an impairment of the electrostatic affinity between the molecules, thus inhibiting their polymerization (Marguerie et al, 1970). The results reported here suggest that this inhibition of fibrin formation may occur in vivo at serum calcium levels which can be observed in clinical conditions of acute hyperparathyroidism.

However, the predominant features of the present 
investigation were the decrease of the clotting time in the thromboelastogram as well as the significantly shorter whole blood clotting times in acute hypercalcaemic rats. The most pronounced difference between the whole blood clotting times of normocalcaemic and acute hypercalcaemic animals was found when contact activation was minimized by the use of polystyrene test tubes. The addition of ellagic acid, a potent activator of Hageman factor (Ratnoff and Crum, 1964), to the blood resulted in an identical shortening of the clotting times of the two groups. Obviously activation of Hageman factor is as efficient in normocalcaemic as in hypercalcaemic animals but the significantly shorter polystyrene test tube clotting time of the hypercalcaemic animals may suggest that partial contact activation has already occurred in vivo. Although no direct evidence was found that hypercalcaemia initiated clotting in vivo, it induced a hypercoagulable state.

The coincidence of thrombotic disorders with hyperparathyroidism has been established by several authors (Mellgren, 1943; Pringle and Smith, 1964; McKay, 1965; Baer and Neu, 1966). Early animal experiments with parathyroid hormone intoxication revealed multiple thromboses at necropsy (Hueper, 1927) and intravascular coagulation was found in our hypercalcaemic tumour animals (Hilgard et al, 1973). These data, in conjunction with the results reported here, seem to indicate that the development of thrombosis may be favoured by an increase in the serum calcium level if additional trigger mechanisms are involved. This fact should be taken into account in the diagnosis and treatment of hypercalcaemic episodes in patients.

\section{References}

Baer, L., and Neu, H. C. (1966). Intravascular clotting and acute pancreatitis in primary hyperparathyroidism. Ann. intern. Med., 64, 1062-1065.

Boyer, M. H., Shainoff, J. R., and Ratnoff, O. D. (1972). Acceleration of fibrin polymerization by calcium ions. Blood, 39, 382-387.

Duffy, J. L., Suzuki, Y., and Churg, J. (1971). Acute calcium nephropathy. Arch. Path., 91, 340-350.

Hilgard, P., Hohage, R., Schmitt, W., and Köhle, W. (1973). Microangiopathic haemolytic anaemia associated with hypercalcaemia in the experimental rat tumour. Brit. J. Haemat., 24, 245-254.

Hilgard, P., Schmitt, W., Minne, H., and Ziegler, R. (1970). Acute hypercalcemia due to Walker carcinosarcoma 256 in the rat. Horm. metab. Res., 2, 255-256.

Hilgard, P., Ziegler, R., Minne, H., and Schmitt, W. (1971). Intravasale Gerinnung beim soliden Walker-Karzinosarkom 256. Schweiz. med. Wschr., 101, 478-480.

Hueper, W. (1927). Metastatic calcifications in the organs of the dog after injections of parathyroid extract. Arch. Path., 3, 14-25.

McKay, D. G. (1965). Disseminated Intravascular Coagulation. Hoeber, New York.

Marguerie, G., Hudry, G., and Hollard, D. (1970). Effets du sodium et du calcium sur la conversion du fibrinogène en fibrine. Thrombos. Diathes. haemorrh. (Stuttg.), 24, 373-384.

Mellgren, J. (1943). Acute fatal hyperparathyroidism. Acta path. microbiol. scand., 20, 693-734.

Minne, H., Ziegler, R., Schmitt, W., and Hilgard, P. (1971). Die hyperkalziämische Aktivität des Walker-Karzinosarkoms 256 bei der Ratte. Schweiz. med. Wschr., 101, 481-483.

Pringle, A., and Smith, E. K. M. (1964). Renal vein thrombosis in acute hyperparathyroidism. Brit. med. J., 2, 675-676.

Ratnoff, O. D., and Crum, J. D. (1964). Activation of Hageman factor by solutions of ellagic acid. J. Lab. clin. Med., 63, 359-377.

Rosenfeld, G., and Jánszky, B. (1952). The accelerating effect of calcium on the fibrinogen-fibrin transformation. Science, 116, 36-37.

Stefanini, M., and Dameshek, W. (1962). The Hemorrhagic Disorders. $A$ Clinical and Therapeutic Approach, 2nd ed. Grune and Stratton, New York and London.

Tocantins, L. M., and Kazal, L. A. (1964). Blood Coagulation, Hemorrhage and Thrombosis. Grune and Stratton, New York, London. 